\title{
Mujeres, agencia política y violencia contrarrevolucionaria en España (1934-1944)*
}

\author{
Sofía Rodríguez López ${ }^{1}$ \\ Universidad de Cádiz \\ sofia.rodriguez@uca.es
}

RESUMEN: Este artículo trata de hacer un repaso por diez años de gran violencia política en España, para comprobar de qué modo las mujeres del bloque contrarrevolucionario participaron de la misma. En contra de lo que se había considerado hasta ahora, las ciudadanas de derechas no fueron meros actores secundarios ni víctimas pasivas de los altercados callejeros y las guerras que se sucedieron entre la insurrección de octubre de 1934 y la retirada de la División Azul del frente ruso. Gracias a una utilización pionera de fuentes de investigación de naturaleza jurídica y militar, como los tribunales de alta traición y espionaje, conservados con la Causa General en Salamanca, o los archivos del SIPM (Servicio de Información y Policía Militar), en Ávila, comprobaremos cómo las españolas formaron parte de la médula espinal del quintacolumnismo que colaboró en la victoria franquista durante la Guerra Civil, desplegando un repertorio de lucha y desobediencia civil genuinamente femenino. Es decir, identificaremos qué puestos ocupaban las mujeres en las labores de sabotaje y boicot a la República y por qué se las escogió a ellas, atendiendo al rol de género de determinadas actividades que resultaron imprescindibles a los sublevados.

PALABRAS ClAVE: mujeres; fascismo; guerra civil; clandestinidad; quinta columna; violencia política.

* Centro Documental de la Memoria Histórica, Salamanca (CDMH); Delegación Nacional de Servicios Documentales, Salamanca (DNSD); Archivo General de la Administración, Alcalá de Henares, Madrid (AGA).

1 ORCID iD: https://orcid.org/0000-0002-3937-7564.

Copyright: (C) 2020 CSIC. Este es un artículo de acceso abierto distribuido bajo los términos de una licencia de uso y distribución Creative Commons Reconocimiento 4.0 Internacional (CC-BY 4.0) 
Women, political agency and counterrevolutionary violence in Spain (1934-1944)

ABSTRACT: This article seeks to review ten years of great political violence in Spain, to determine the role played by women in the counterrevolutionary bloc. Contrary to what had so far been believed, right-wing citizens were not mere supporting players or passive victims of the street riots and the wars that took place between the October 1934 insurrection and the Blue Division's withdrawal from the Russian front. Adopting a pioneering approach to research sources of a juridical and military nature-such as the high treason and espionage courts, kept with the Causa General in Salamanca, or the SIPM files in Avila -we will show how these Spanish women became instrumental fifth columnists who collaborated in Franco's Civil War victory, deploying a specifically female repertoire of struggle and civil disobedience. We will identify jobs undertaken by women in the sabotage and boycott of the Republic and why they were chosen to play this part, noting how gender roles in certain activities proved essential to the rebels.

KeY WORds: Women; Fascism; Civil War; Secrecy; Fifth Column; Political violence.

CÓMO CITAR ESTE ARTÍCULO/CITATION: Rodríguez López, Sofía, «Mujeres, agencia política y violencia contrarrevoluacionaria en España (1934-1944)», Hispania, 80/265 (Madrid, 2020): 531-561. https://doi.org/10.3989/hispania.2020.015

La participación de las españolas en los principales acontecimientos de la Segunda República, la Guerra Civil y la posguerra inmediata dependería de las trayectorias y culturas políticas a las que se habían ido incorporando desde comienzos del siglo XX. Este estudio se centrará en las mujeres de los sectores reaccionarios a las reformas social-azañistas y en el despliegue de un repertorio de lucha que no se redujo a la resistencia civil, sino que colaboró directamente en la «guerra sucia». Empleando literatura y fuentes primarias, realizaremos un recorrido por los escenarios donde las católicas abandonaron su tradicional rol de pacificadoras para involucrarse en la lucha armada o en actividades de información militar. Y, para evitar el adanismo, partiremos de unos referentes internacionales de combatividad femenina, católica y contrarrevolucionaria, a los que no se había prestado especial atención hasta ahora.

\section{LA EXPERIENCIA MEXICANA DE LAS MUJERES EN LA GUERRA Cristera}

Aunque cada vez contamos con más estudios comparados de las guerras civiles desencadenadas tras 1918, las intentonas revolucionarias que emulaban a los bolcheviques, o los regímenes totalitarios implantados en la «Europa Negra», rara vez vinculamos la crisis de los años treinta en España con el otro 
lado del Atlántico, salvo notables excepciones como las de Manuel Suárez Cortina o Julio de la Cueva ${ }^{2}$. Sólo cuando abordamos el exilio, volvemos la mirada hacia América Latina y el México de Lázaro Cárdenas, como el apoyo más decidido a esa República moribunda. Sin embargo, existen paralelismos entre las trayectorias de ambas naciones y un claro ascendiente femenino, tanto para las milicianas antifascistas, por sus soldaderas o «Adelitas», como entre quintacolumnistas y cristeras $^{3}$.

La escalada de violencia que se produjo en España a raíz de la quema de conventos en mayo de 1931 y las medidas secularizadoras del gobierno de Manuel Azaña estaban demasiado próximas al final de la Cristiada en 1929 como para obviar las casi 250.000 víctimas, laicas y religiosas, movilizadas en contra de la Ley Calles y la Constitución de 1917, que prohibían el culto católico en público ${ }^{4}$.

Autoras como Inmaculada Blasco o Rebeca Arce han presentado el catolicismo social como catalizador de la nacionalización e inclusión de las españolas en la política de masas, durante el primer tercio del siglo XX, mostrando los efectos que tuvo la Constitución de 1931 en el sentimiento de millones de hombres y mujeres de este país. Pensemos entonces que si esto provocó un distanciamiento con la República de Irlanda, por ejemplo, contraria a sacrificar su cultura católica por reformas sociales, México sentiría que su propia historia se repetía en la madre patria con fuerzas renovadas ${ }^{5}$.

Numerosas mexicanas desafiaron al anticlericalismo estatal durante los tres años de Guerra Cristera (1926-1929), mostrándonos que la resistencia cotidiana no solo se asocia a las opciones transformadoras de izquierdas, y exige una comprensión más amplia de la marginalidad, las relaciones de poder y el papel político de las organizaciones católicas femeninas. Su participación en este levantamiento confesional contra el gobierno del masón Plutarco Elías fue ignorada por los historiadores hasta que en los años ochenta varias investigadoras anglosajonas como Barbara Miller, Jean Meyer o Eileen Findlay hicieron sus doctorados sobre este sujeto político emergente, manteniendo entrevistas con algunas de sus protagonistas y revelando la transformación de su papel tradicional en la Iglesia a partir de 1920. Demostraron que podían asumir el liderazgo en una empresa violenta para volver después a sus roles tradicionales, como sucedió también en el franquismo ${ }^{6}$.

La Unión de Damas Católicas Mexicanas (UDCM) fue una de esas organizaciones que, en el contexto de la Rerum Novarum, utilizó medios como la

\footnotetext{
${ }^{2}$ MAZOWER, 2001. SUÁREZ CORTINA, 2014. DE LA CUEVA MERINO, 2017.

3 SCHELL, 2012.

${ }^{4}$ NÚÑEZ DÍAZ-BALART, 2017. SUÁREZ CORTINA, 2013: 157-196.

5 BLASCO HERRANZ, 2003. ARCE PINEDO, 2008. Sobre Irlanda, JASPE, 2011.

${ }^{6}$ MILLER, 1984
} 
educación vocacional, la organización sindical y diversas campañas de moralidad para responder a los cambios en la sociedad precipitados por la revolución de 1910-1917. Siendo imposible la cooperación con feministas y socialistas, por el anticlericalismo imperante, su papel en Ciudad de México se fue radicalizando con el tiempo, pasando de evitar los enredos políticos a protagonizar enérgicas protestas?.

Por su parte, las muchachas de la Juventud Católica Femenina Mexicana (JCFM) utilizaron los medios de comunicación para difundir ideologías reaccionarias que combatieran los proyectos izquierdistas del Estado. Ellas protagonizaron una historia de oposición y transformación que conectaría el conflicto social cristero con los enfrentamientos político-culturales de la Guerra Fría. A través de sus revistas y campañas pedagógicas, la JCFM consiguió movilizar a maestras, estudiantes, campesinas, obreras y empleadas domésticas, aunque la base ideológica del feminismo católico no consiguiera salvar las enormes desigualdades de raza y clase que existían en el seno de este movimiento político ${ }^{8}$.

En cualquier caso, como ha mostrado Claudia Quezada, las michoacanas tuvieron una enorme relevancia como proveedoras de armas, municiones y noticias entre diferentes grupos, así como en la conservación de bienes y propiciación del culto católico clandestino, sin importarles las consecuencias que dichas acciones pudieran tener ${ }^{9}$. Una labor que, una vez más, sería emulada por las margaritas tradicionalistas en el socorro blanco y la quinta columna de la guerra civil española. Como ha expuesto Julio de la Cueva, su experiencia demostró que era posible pelear, morir y matar por Cristo Rey, hasta el punto de que los/as mártires mexicanos/as se convirtieron en un modelo para las religiosas españolas. Ése sería el caso de tres carmelitas descalzas de Guadalajara asesinadas en julio de 1936, que se entretuvieron durante la República realizando dramatizaciones exaltadas del heroísmo cristero ${ }^{10}$.

La cultura política que impregnaba al Vaticano y al catolicismo español de la época, basada en las vidas ejemplares de los santos, conminó a «leer» los acontecimientos históricos del momento desde una perspectiva que situaba en un mismo plano a la Unión Soviética, el México contrarrevolucionario y el anticlericalismo de la Segunda República en España.

Este vínculo se puede rastrear también en la trayectoria del Partido Nacionalista Español fundado en 1930 por José María Albiñana, tras llegar a Madrid expulsado por Plutarco Elías. Considerado como el primer caudillo del

7 SCHELL, 1999.

8 ÁLVAREZ-PIMENTEL, 2017.

${ }^{9}$ QUEZADA QUIROZ, 2012.

10 DE LA CUEVA MERINO, 2012 y https://www.casadevelazquez.org/recherche-scientifique/news/la-cristiada-entre-los-catolicos-espanoles-recepcion-e-incorporacion-a-un-imaginario-contrarrev/ [consultado el 12/02/2020].

Hispania, 2020, vol. LXXX, n. ${ }^{\circ}$ 265, mayo-agosto, págs. 531-561, ISSN: 0018-2141, e-ISSN: 1988-8368 https://doi.org/10.3989/hispania.2020.015 
fascismo en España, estaba tan próximo a la «nueva derecha europea» como a los carlistas, somatenes y Legionarios de Cristo, y concebía la Cristiada como la respuesta más gloriosa del pueblo católico a la opresión revolucionaria. Asiduo a periódicos como La Nación o El Debate, describió también en sus ensayos y novelas el desarrollo de esa «guerra santa», mientras ejercía la medicina en su clínica del D.F. Recibido con oropeles al final de la dictadura de Miguel Primo de Rivera, el doctor Albiñana crearía una sección femenina en torno a la Sociedad Aspiraciones que, inspirada por esas mujeres michoacanas, suscitaba pocas sospechas en la gestión de pistolas y bombas de mano con destino a la Sanjurjada en $1932^{11}$.

Ya al término de la Guerra Civil y una década después de la rebelión Cristera, en 1939, algunos personajes de la vida académica y política mexicana, como Manuel Gómez Morín y Efraín González Luna, fundaron allí el Partido Acción Nacional. Las secciones femeninas del mismo, con fuerte presencia también de la Acción Católica, volvieron a mostrar esa doble vertiente tradicional y transgresora en lo público, al combinar el asistencialismo caritativo con la divulgación y reparto de propaganda electoral. La ciudadanía de las mujeres, como expone Vera García, volvía a transitar así entre el ejercicio del sufragio, la función pública y la acción social, fórmula que podemos extrapolar a la España de posguerra sin dificultad ${ }^{12}$.

\section{OCtubre de 1934: La Sección Femenina y la «Dialéctica de los puños Y LAS PISTOLAS»}

Una vez documentada la relación evidente entre la acción-reacción católica y contrarrevolucionaria de las mujeres movilizadas a ambos lados del Atlántico, podemos afirmar que la participación de las españolas en los principales escenarios de violencia política durante la República se inició en 1931, pero destacó a partir de octubre de 1934. Unos meses antes se habían constituido las dos organizaciones más combativas del momento: en febrero, Dolores Ibárruri se puso al frente del Comité Español de Mujeres contra la Guerra y el Fascismo, y en julio, una minúscula Sección Femenina de Falange (en adelante, SF) congregaría en Madrid a las hermanas y primas de José Antonio Primo de Rivera, apenas siete personas, como única representación de los Fasci Feminile que afloraban por toda Europa ${ }^{13}$.

Si la represión de la insurrección obrera en Asturias movilizó a las esposas e hijas de los mineros, como soporte material primero, y a favor de la amnistía

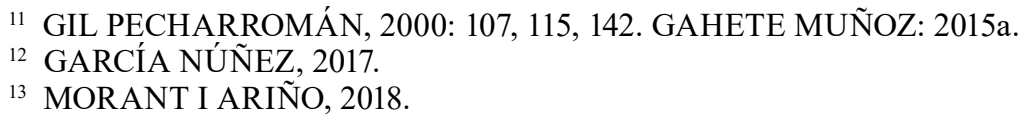


de los presos, después, las mujeres del requeté, la Acción Popular o el monarquismo posibilista no habrían de quedarse atrás. De modo que, como se observó en 1936, existiría una línea de continuidad entre la represión de la huelga general revolucionaria y las acciones de esa primavera sangrienta ${ }^{14}$.

Como señala Brian D. Bunk, la narrativa aparecida entonces victimizaba a las mujeres como seres pasivos a las que defender, para proteger su honor, o violar en las razias de las tropas africanistas. No obstante, aunque la mayoría de representaciones negara el liderazgo femenino, los casos de violencia emprendida por mujeres de uno y otro bando con un rol activo se justificaron apelando a su «conciencia femenina» como esposas, o a una suerte de «ciudadanía maternal» ${ }^{15}$.

No se tienen datos exactos sobre los niveles de participación militar o «acción directa» femenina en 1934, pero las historias particulares de estas heroínas afloraron rápidamente, haciendo de la joven comunista Aída Lafuente el mito fundacional de una genealogía de luchadoras ${ }^{16}$. El «bautismo de fuego» en el uso, transporte y ocultación de armas, así como los contactos con el ejército y los cuerpos de seguridad, obedecía, entre otras causas, a las instrucciones socialistas sobre el uso de mujeres y niños para «trabajos fáciles» como el de enlaces, por el que tantas mujeres fueron detenidas en Madrid. Y fue ese contexto de violencia revolucionaria y anticlerical en España, como se vivió antes en México, el que propició un movimiento femenino antifascista, moderno y de masas, tal y como lo denomina Mercedes Yusta, a la par que un movimiento fascista/reaccionario muy minoritario pero pujante, como el de las falangistas españolas ${ }^{17}$.

Aunque a las «mujeres de orden» se las tratara de mantener alejadas de la «alta política», incluso las monárquicas y republicanas de Acción Popular habían alcanzado un bagaje de movilización y propaganda anti-azañista en los años previos, difícil de olvidar. Garantes de la tradición católica y la familia, como bases del Estado nacional, éstas se aliaron con los «sindicatos amarillos» y el apostolado seglar en su propia cruzada contrarreformista de las escuelas, el Código Civil y el Penal ${ }^{18}$.

Ellas representaron una masa católica soliviantada por las reformas secularizadoras del Estado ya en 1931, cuando se quemaron las primeras iglesias. Tal fue el caso de las madres y esposas de los guardias civiles de Benaguacil (Valencia), que se amotinaron contra la prohibición de las procesiones

${ }^{14}$ BUNK, 2007: 71, 85, 87, 96.

15 Los conceptos de «conciencia femenina» y «ciudadanía maternal» son de KAPLAN (1990) y ELEY (2003).

16 BUNK, 2007: 129-131, 134-149.

17 SOUTO KUSTRÍN, 2004: 222 y YUSTA RODRIGO, 2013.

18 ORTEGA LÓPEZ, 2008. AGUADO HIGÓN y ORTEGA LÓPEZ, 2011. 
callejeras, hasta arrancar los fusiles de las manos de sus maridos ${ }^{19}$. No obstante, fue en ese contexto de 1934 cuando explosionaron los llamamientos a las conservadoras para movilizarse en defensa de su hogar y su familia. Los escritores Adro Xavier o Jenaro Geijo las conminaron a protegerse del contagio de la propaganda comunista, siguiendo el ejemplo de la asturiana Julia Fraigedo, que murió luchando junto a su marido en Ciaño. Según otro texto atribuido a los «prisioneros de Asturias», un grupo de mujeres católicas se alistaron como enfermeras de los mineros heridos para matarlos con sobredosis de medicamentos. $\mathrm{Y}$ es que, como puso de manifiesto Temma Kaplan, estos relatos demuestran la controversia que provocaba en los hombres la alteración del orden sexo-género que la República trajo consigo ${ }^{20}$.

Los obituarios de Rosa Bríos Gómez, una telefonista turolense asesinada en 1937, indicaban que desde enero de 1934 bordó camisas, insignias y banderas fascistas. Se dice que «al poco tiempo, esta mujer se convirtió en el pilar más fuerte de la Falange de Alcañiz, por el apoyo moral que prestaba a los camaradas en los momentos más difíciles». De hecho, cuando José Antonio dio un mitin en esta localidad de mayoría anarquista el 5 de enero de 1936, Rosa fue la encargada de organizarlo todo, decorando el local y ocultando las armas de los camaradas detenidos al término del acto ${ }^{21}$.

En las filas del fascismo más genuino, la primera sección femenina del SEU se uniría a las albiñanistas como Dora Maqueda y a la única afiliada jonsista, Justina Rodríguez de Viguri, para desafiar la prohibición inicial de Ramiro Ledesma y José Antonio Primo de Rivera de admitir mujeres en su seno. Desde junio de 1934, el único objetivo de la SF de FE y de las JONS sería encargarse de la propaganda, ya que ellas asumían menos riesgos que los hombres. Los continuos altercados callejeros que provocaban japistas y falangistas habían conllevado ya la clausura de delegaciones locales como la de Sevilla por el ministro de Gobernación, Casares Quiroga, así como las primeras detencio$n^{22}{ }^{22}$ Y en paralelo a lo que hacían las antifascistas con los presos políticos de Asturias, las falangistas asumieron la función clandestina de proporcionarles comida y tabaco a los suyos, recaudando hasta 15 pesetas por familia, mediante la venta de jabón, rifas y sellos de cotización.

A finales de 1934 eran ya 300 muchachas las que acudían a los locutorios de las cárceles en calidad de novias o hermanas de los detenidos, muchos de los casi 5.000 jóvenes que consiguieron afiliarse, pese a la generalizada prohibición paterna. «De hecho, el número de muertos falangistas crecía sin cesar y la conciencia del peligro era directa y real», así pues, tras los anuncios reiterados

\footnotetext{
${ }^{19}$ URIBARRI, 1943: 118-122.

${ }^{20}$ KAPLAN, 2002.

${ }^{21}$ SÁNCHEZ BLANCO, 2016: 77-80.

${ }^{22}$ LOWE, 2000: 20-22.
} 
de una revolución marxista contra «las fieras del régimen capitalista», se comprende que «cuando los padres descubrían en sus hijas intenciones de afiliarse a la Sección Femenina, se asustasen ${ }^{23}$.

Asturias fue el punto de inflexión para el aumento de la militancia en 1935 entre muchachas provenientes de familias acomodadas y de derechas en Madrid, Sevilla, Navarra, Jerez, Zaragoza, Pamplona o Salamanca, donde ficharon a la hija del tradicionalista Lammamié de Clairac. Más importantes serían las nuevas tareas encomendadas como enlaces, distribuidoras de periódicos y propaganda electoral en las 19 provincias a las que presentaron candidatos. Fue entonces cuando la delegada de Vigo, María Dolores Ozores, avisó a Pilar Primo de Rivera de que se estaban produciendo las primeras detenciones de mujeres, caso de Josefina Fernández Acoitia y María Teresa Masenet, acusadas de alborotar las calles y los juicios contra sus «camaradas», así como de convertir sus entierros en manifestaciones de oposición al Gobierno ${ }^{24}$.

El primer estatuto de SF, dictado por una circular de José Antonio en diciembre de 1934, les encargaba también la elaboración de brazaletes y banderas, como los que venía haciendo la citada Rosa Bríos. Emblemas que se unirían a su recién compuesto himno, «Cara al Sol», que se cantó por primera vez en Segovia durante una visita de Pilar a las tres hermanas de Dionisio Ridruejo. No obstante, el momento crucial para ellas se produciría después de las elecciones que ganó el Frente Popular, cuando el 14 de marzo de 1936 se ilegalizó Falange Española y se procedió al encarcelamiento de su junta política, tras los altercados por el atentado fallido contra Luis Jiménez de Asúa. Puede decirse que entonces la SF tuvo que echarse sobre sus espaldas al partido ${ }^{25}$.

Esa «primavera sangrienta» la mayoría de células falangistas serían desmanteladas y su jefa nacional escondida por amenaza de muerte, tras encontrar armas en su augusta casa. También fue acusada entonces de haber participado en la muerte de la joven socialista Juanita Rico en junio de 1934, por lo que delegó en sus correligionarias la propaganda para la segunda vuelta de las elecciones, con la esperanza de que José Antonio pudiera obtener la inmunidad parlamentaria. No obstante, tanto los mítines de esos meses como la derrota en los comicios se convirtieron en actos violentos, en los que fueron las propias mujeres quienes introdujeron porras y pistolas escondidas en el forro de sus abrigos y botas katiuskas ${ }^{26}$.

Refugiada en varias capitales, antes de llegar a la Trilingüe salmantina, Pilar Primo de Rivera envió una circular ordenando a las delegadas que

${ }^{23}$ SUÁREZ FERNÁNDEZ, 1993: 28-36. GAHETE MUÑOZ, 2015 b.

${ }^{24}$ SUÁREZ FERNÁNDEZ, 1993: 49.

25 BARRERA LÓPEZ, 2019: 40-46.

${ }^{26}$ Sobre la muerte de Juanita Rico: SOUTO KUSTRÍN, 2004: 140-141. GINARD FERÓN, 2015: 107, 111.

Hispania, 2020, vol. LXXX, n. ${ }^{\circ}$ 265, mayo-agosto, págs. 531-561, ISSN: 0018-2141, e-ISSN: 1988-8368 https://doi.org/10.3989/hispania.2020.015 
siguieran con la recaudación, para no suponer una carga al partido. Pero su labor no se quedaría ahí. Destacadas camisas viejas como Carmen García del Salto, herida en Cádiz, y, sobre todo, Marjorie Munden, con pasaporte británico, se ocuparon de la obtención de pistolas y armas largas para entregar a las milicias en Valladolid, antes de la sublevación militar.

\section{JULIO DE 1936: LAS MUJERES DE LA QUINTA COLUMNA}

Tras el levantamiento y el Decreto de Unificación en Falange Española Tradicionalista y de las Juntas de Ofensiva Nacional Sindicalistas, JONS (FETJONS), en abril de 1937, «margaritas» y damas de la caridad fueron cediendo protagonismo a los «ángeles azules» de la Falange. Jóvenes activistas también que, frente a las «rojas», hicieron suya la bandera contrarrevolucionaria de la fe sin armas y desde los púlpitos del Auxilio Social ${ }^{27}$.

Más allá de la actuación oficial en comedores, enfermerías o lavaderos del frente, tanto fascistas como antifascistas se implicaron en actividades de naturaleza política, condenadas por la España que les tocó en suerte durante el conflicto. Es decir, hubo mujeres que, emulando el acervo de protestas femeninas recogidas desde la Revolución Francesa, la Guerra de Independencia o la de Marruecos, desarrollaron actos de auténtica violencia política y desobediencia civil. Ésta podía emplearse con luz y taquígrafos, en el asalto a las tahonas o la obstrucción al reclutamiento de sus hijos; o de forma clandestina, colaborando con sus ejércitos y dirigentes en el boicot a la legalidad vigente ${ }^{28}$.

Mientras que el primer tipo de actuaciones podríamos enmarcarlas en los repertorios internacionales del «maternalismo social» y las «armas de los débiles», las segundas conforman una estrategia conocida por un término genuinamente español y acuñado en 1936, el de «quinta columna» ${ }^{29}$. Han sido muchos los autores que, desde su origen, lo han empleado para referirse a la población civil madrileña que se uniría a las cuatro columnas de insurgentes en la conquista de la capital ${ }^{30}$. Las actividades de esta organización informal, surgida allí poco después del 18 de julio, y emulada rápidamente en otras ciudades republicanas, eran descritas por la prensa a diario. El objetivo del Estado legítimo era que todos los «ciudadanos conscientes» conocieran

27 RODRÍGUEZ LÓPEZ, 2010; 2009.

28 DEL MORAL VARGAS, 2012. RAMOS PALOMO, 2000.

29 SCOTT, 1987. NÚÑEZ DE PRADO, 1989.

${ }^{30}$ PALACIO ATARD, 1970. ALCOCER BADENAS, 1976. Como fuentes primarias: Hemingway, Ernest, La Quinta Columna, Madrid, 1938; Carretero, José M., La Quinta Columna, Madrid, 1940. 
su modus operandi y se implicasen en la delación, poniendo rostro a los emboscados que difundían bulos desmoralizadores ${ }^{31}$.

Dicho esto, podría pensarse que la quinta columna implicó sólo a las españolas de derechas, mientras la «acción directa» se reservó a las de izquierdas, y no es del todo cierto. Lo que aquí queremos demostrar es que las mujeres de cualquier ideología se movieron con especial fluidez en los medios clandestinos, por razones culturales y de género, aunque el paradigma de la resistencia al poder legítimo estuvo dominado por las reaccionarias. El hecho evidente es que encontramos a éstas últimas liderando varias redes quintacolumnistas en Madrid, Barcelona, Valencia o Almería.

No hay un único por qué del protagonismo femenino en este tipo de actividades, porque éstas tienen que ver con las identidades en conflicto durante la Guerra Civil. Si atendemos al sentimiento de clase, vemos cómo las mujeres de extracción humilde, más o menos vinculadas al movimiento obrero, se sentían legitimadas por lo que el marxismo británico denominó la «economía moral de la multitud $»^{32}$. Es decir, vieron en la detracción de los derechos recién conquistados durante el segundo bienio republicano, el marco de injusticia por el que implicarse en la lucha por la reforma agraria o la revolución de Asturias. Por su parte, las españolas acomodadas se sentirían igualmente amparadas por otra «economía moral», la del padre Francisco de Vitoria. Un concepto de la escolástica que, como el «Derecho de gentes» o el De iure belli, serviría para aplacar la supuesta tiranía impuesta por el Frente Popular. Esa idea de la «guerra justa» las escoltó hasta la sublevación militar, entendida como respuesta a unas clases populares dispuestas a acabar con sus privilegios ${ }^{33}$.

Pero, una vez desencadenado el conflicto, esa misma gente - entendida ahora como casta política - tuvo que lidiar en terrenos menos honorables que el de las armas, destino por excelencia de todo caballero español ${ }^{34}$. Como indica Anna Bravo, refiriéndose a la resistencia italiana, es necesario repensar los binomios de «activo/pasivo, armado/sin armas, digno/indigno, valiente/ cobarde» que hemos heredado de tradiciones enraizadas en el tiempo, y sobre las cuales reposa una idea de nación estrechamente ligada a la virtud militar ${ }^{35}$. Por ello fue tan importante la participación femenina en «la trastienda». No estando reservado para ellas el uso de la violencia ni la defensa del honor, se

${ }^{31}$ Por ejemplo: «La quinta columna en Cataluña», Frente Rojo, I/206 (17-9-1937) y Contreras, Carlos, La Quinta Columna. Cómo luchar contra la provocación y el espionaje, Valencia, 1938.

${ }^{32}$ THOMPSON, 2001. SCOTT, 1977. POWELSON, 1998.

33 FAZIO FERNÁNDEZ, 1998. BELDA PLANS, 2013: 323-333. La legitimación del golpe de Estado desde la filosofía del derecho y su interpretación judicial en FERNÁNDEZ CREHUET y GARCÍA, 2009. LANERO TABOAS, 1996.

${ }^{34}$ PASTOR PETIT, 2013: 376, 397.

35 BRAVO, 1995. LÓPEZ MARTÍNEZ, 2012. 
movieron sin sentimiento de culpa o traición por espacios que les eran familiares por su escaso protagonismo social: desde los mercados y porterías más frecuentados, hasta las reboticas y los secretos de alcoba.

Así lo entendieron algunos protagonistas de la propia guerra, como el presidente de la República, Manuel Azaña, o el director del Servicio de Investigación Militar (SIM) encargado de la persecución de los emboscados, Manuel Uribarri, quien definió al «elemento femenino per se... [como] el entronque de la quinta columna», hasta el punto de que «por cada quintacolumnista, hubiéramos tenido que detener diez mujeres $\rangle^{36}$.

Nuestra tesis principal es que las antifascistas de las zonas donde fracasó el golpe tomaron la iniciativa de las armas pero, una vez desplazadas del Ejército Popular, se ocuparon mayoritariamente de la «política legal» en su retaguardia. En la zona franquista, las antifascistas fueron represaliadas hasta el punto de no existir apenas demostraciones de resistencia clandestina, a excepción de algunas colaboradoras de la guerrilla; el DEDIDE, Departamento Especial de Información del Estado, dependiente de Gobernación, o el SIM creado por Indalecio Prieto ${ }^{37}$.

Las contrarrevolucionarias tampoco se limitaron a curar las heridas de sus combatientes y utilizar el pan blanco como propaganda, sino que amén del activismo de Sección Femenina en las enfermerías y lavaderos del frente nacionalista, crearon vastas redes de resistencia. Las formas en que esta otra «política ilegal» de oposición a la República se desarrolló en zona gubernamental, fueron dos, coincidiendo con dos etapas bien diferenciadas de la guerra. La primera consistiría en la articulación de esa primigenia «quinta columna», surgida de forma espontánea en las ciudades leales para atender a los perseguidos de derechas, como fue el caso de la Delegación Especial para la Información de Residentes en Territorio Liberado (DIDREM), creada en Madrid en noviembre de 1936. Y la segunda aparecería en el otoño de 1937, tras la centralización de los servicios de inteligencia franquistas, como resultado de la «militarización» de esas quintas columnas. Finalmente, nos ocuparemos de las mujeres que trabajaron en las oficinas de la Delegación de Recuperación de Documentos (DERD), encargadas de procesar la información sobre los «rojos» para su represión ${ }^{38}$.

En primer lugar nos referiremos al fenómeno quizás menos conocido, el de una mujer de derechas que combatiría directamente con las armas, llegando a obtener a título póstumo la Cruz de Guerra, por Orden de 24 de abril de 1940. Éste sería el caso de la turolense Agustina Simón Sanz, vinculada a los círculos tradicionalistas y que, nada más estallar el conflicto, se lanzó a la calle con su

\footnotetext{
${ }^{36}$ URIBARRI, 1943: 119-124.

37 RODRÍGUEZ VELASCO, 2012: 137.

${ }^{38}$ RODRÍGUEZ y CAZORLA, 2018: 692-713.
} 
hermana para repartir equipos a los voluntarios navarros que se fueron aproximando a Zaragoza. Pasó después a la enfermería del Hospital del Salvador, «pero el afán de Agustina era servir en el frente: siempre lo había dicho — si hay alguna guerra me iré con los requetés - . Tras visitar el sector de Belchite, solicitó un puesto en el Seminario, la más avanzada y peligrosa de todas las posiciones $\rangle^{39}$.

Efectivamente, el 24 de agosto de 1937, la que sería rebautizada como nueva Agustina de Aragón en Belchite (como nombraron a Aída Lafuente en 1934), se incorporaba voluntaria al Tercio de Almogáraves, donde atendió a los soldados y heridos, a la vez que «cargaba los fusiles» como las cristeras. Cuando cayó presa junto al capellán y 15 requetés más, utilizó un argumento clásico para justificar su presencia en el frente junto a sus hermanos, pero éste no bastó para evitar el fusilamiento apenas diez días después de ser movilizada.

Este caso pasó a glosar las memorias de las Damas Auxiliares de la Sanidad Militar, junto a las denominadas «mártires» del Hospital de Sangre de Somiedo. Pero los servicios más importantes de «blancas y azules» se centraron, desde entonces, en las primeras organizaciones civiles de inteligencia creadas al margen de los servicios secretos de las segundas secciones del Ejército ${ }^{40}$.

El 8 de noviembre de 1936, tras la creación de la Junta de Defensa de Madrid, Fal Conde constituyó la Oficina de Información y Enlace de la Comunión Tradicionalista. Mientras tanto, el Conde de los Andes había fraguado el Servicio de Información del Nordeste de España (SIFNE) en el País Vasco francés. Se valió para ello de un lobby de monárquicos alfonsinos como Quiñones de León, su enlace en París, y catalanistas de la Lliga Regionalista como su mecenas, Francesc Cambó, y el abogado José Bertrán i Musitu ${ }^{41}$.

Tras la puesta en funcionamiento de todo ese engranaje, Franco llegó a obsesionarse con su centralización, bajo control del Ejército. Una fusión que se formalizaría a través de la orden reservada de creación del Servicio de Información y Policía Militar (SIPM) el 30 de noviembre de 1937, y el decreto de desaparición del SIFNE, el 28 de febrero de 1938.

Lo más interesante de esta red de información para el boicot a la República fue que resultó una canonjía de magníficos resultados para los golpistas. Financiada por algunas de las mayores fortunas del país, como el referido Cambó, Juan March y el marqués de Luca de Tena, estuvo además compuesta por numerosos voluntarios provenientes de las antiguas milicias urbanas de Acción Ciudadana, Somatén y requetés, fuera de edad militar, así como ex policías, carabineros en activo, ingenieros y mujeres jóvenes en cumplimiento del Servicio Social. Todos ellos entrarían en connivencia con las autoridades portuarias y funcionarios de la

\footnotetext{
39 SÁNCHEZ BLANCO, 2016: 146, 150.

40 NÚÑEZ DE PRADO, 1992. HEIBERG y ROS, 2006.

${ }^{41}$ BERTRÁN I MUSITU, 1940. PASTOR PETIT, 1978.
} 
Administración General del Estado, desde Hacienda y Justicia, hasta Agricultura. El personal más preparado de España, desde su cuerpo diplomático a los subalternos, trabajando gratis para socavar la resistencia del Gobierno ${ }^{42}$.

El SIFNE tenía su sede en Biarritz y disponía de una oficina carlista de enlace instalada en la Villa «Nacho Enea» de San Juan de Luz, para regular la entrada de viajeros y, con ellos, administrar información, pasaportes y ayudas económicas de vital importancia para los sublevados. Allí disponía de cartografía, servicio de escuchas, criptografía y descifrado, así como análisis de prensa extranjera y republicana, a través del «buzón del miliciano» ${ }^{43}$. No obstante, su red de observadores se extendía mucho más allá, manteniendo comunicaciones oficiales desde Marsella hasta el Bósforo, Rotterdam o el Canal de la Mancha, con agentes como el Duque de Alba en Londres. El envío de información se hacía a través de valija diplomática, gracias a la connivencia de las embajadas, los infiltrados en Correos y Telégrafos, los teléfonos atendidos por muchachas y las radios clandestinas. Su éxito se debía, finalmente, a la ayuda exterior obtenida de las agencias internacionales de información militar y policía secreta: la Abwehr (en alemán, "defensa") de Canaris, operativa entre 1921 y 1944; la italiana OVRA (Organizzazione per la Vigilanza e la Repressione dell'Antifascismo, 1927-1945), y el PVDE del Estado Novo portugués (Polícia de Vigilância e Defensa do Estado, 1933-1945). Una colaboración debida, en parte, a la labor como diplomático de Nicolás Franco, embajador en Roma y Lisboa entre 1937-3844.

La principal misión del SIPM sería detectar los movimientos de tropas y tareas estrictamente relacionadas con la guerra. Una vasta maquinaria complementada con equipos de contraespionaje y sabotaje de los guerrilleros antifascistas. $\mathrm{Y}$ es que «en su momento óptimo el SIPM contó con unos 30.000 hombres», provenientes en su mayoría de la quinta de 1929, junto a los voluntarios civiles de hasta 45 años, jóvenes soldados de reemplazo, y guardias civiles para las misiones más arriesgadas ${ }^{45}$.

¿Dónde habían quedado, para entonces, las mujeres?

\section{NOVIEMBRE DE 1936: LAS CATÓLICAS Y EL ESPIONAJE}

Comenzaremos por la Delegación Especial para la Información de Residentes en Territorio Liberado (DIDREM), creada en Madrid en noviembre de 1936 por José Fariña Ferreño, y extendida, en marzo de 1937, a toda España. En ella

\footnotetext{
${ }^{42}$ BARRUSO BARÉS, 2008.

${ }^{43}$ RODRÍGUEZ y CAZORLA, 2018: 709-710.

44 PALACIO ATARD, 1970: 263.

${ }^{45}$ NÚÑEZ DE PRADO, 1992: 178
} 
actuaría María de Madariaga y Alonso, de 31 años y presidenta de la Juventud Femenina de Acción Católica desde 1926, así como fundadora de la Hermandad de Enfermeras Católicas Salus Infirmorum.

Cuando en febrero de 1938 la organización pasó a depender del primer Ministerio de Orden Público, ya tenía establecidas en la capital y otras ciudades leales «oficinas de barrio», ubicadas a pie de calle junto a las iglesias y abiertas en horario de mañana y tarde, para acoger colaboradores permanentes o accidentales que ofrecían una cantidad ingente de información sobre las personas conocidas que habían quedado atrapadas en la España republicana. Aunque su función parecía obedecer a fines humanitarios de reencuentro, similares a los que ejercía el Altavoz del Frente en el otro bando, pronto se demostró que aquellas oficinas proporcionaban auténticas bases de datos para la ingente trama informativa de los sublevados ${ }^{46}$.

Según el informe elaborado en 1939 por uno de los jefes de la DIDREM, Manuel Antonio García Alegre, entre esos colaboradores permanentes había 75 hombres y una sola mujer. Pero en las oficinas auxiliares ellas representaban casi el $20 \%$ de los 131 miembros, y dentro del grupo exclusivo de los informadores de Acción Católica fueron clara mayoría, 29 de un total de 33 miembros. La encargada de reclutarlas fue María de la Concepción Sanchiz Calatayud, miembro del Consejo Superior de dicha Confederación de Mujeres Católicas y vicepresidenta de propaganda del mismo desde febrero de 1937.

No sabemos a qué cantidad total de efectivos nos referimos, ya que sólo se cuenta con 219 nombres entre las 625 personas registradas, la mitad de ellas en Madrid. Al igual que sucedía con los «comités de casas» republicanos, controlados desde las porterías ${ }^{47}$, éstas eran agentes de información que operaban por parejas, identificados con carnés o brazaletes para realizar entrevistas cortas de no más de diez minutos, en las que se registraban por calles los datos censales de las personas supervisadas ${ }^{48}$.

Más allá de la atención sanitaria, las mujeres de la Delegación de Frentes y Hospitales, liderada por Rosa Urraca Pastor, también se implicaron en el DIDREM, que llevó a establecer una oficina estratégica en Fuenterrabía, frontera del País Vasco francés. A ella pertenecerían Esperanza García Alegre, hermana del dirigente Manuel García Alegre, o María de Cárdenas, quien, en febrero de 1939 se dirigía a la inspectora general femenina de dicha delegación, Mercedes Milá Noya, expresando su deseo de entrar en Madrid «para ayudar sobre todo en organizaciones de información, pues tú sabes muy bien lo mucho

\footnotetext{
${ }^{46}$ CERVERA GIL, 1998.

${ }^{47}$ OVIEDO SILVA, 2016. GÓMEZ BRAVO, 2017: 118-159, 266-295.

48 RUIZ-BERDÚN et al., 2016.
} 
que me he ocupado de esto, y mi actitud y conocimientos en ficheros, etc., $\mathrm{y}$ cómo conozco el barrio de Salamanca ${ }^{49}$.

Mientras los equipos de informadores masculinos se encontraban sobre todo en las embajadas diplomáticas, ayuntamientos, cuarteles, registros y juzgados, centros oficiales, políticos u obreros, así como en los cementerios, bancos, casinos, prensa y comunicaciones, compañías de seguros, notarías y otros órganos colegiados, las mujeres se movían con mayor fluidez e invisibilidad en el entorno de los cuidados: colegios y sanatorios de diverso tipo, manicomios, asilos, conventos e iglesias parroquiales. La colaboración documentada en estos servicios informativos serviría a muchas de esas mujeres, provenientes tanto del tradicionalismo católico como de la Falange clandestina, como convalidación del Servicio Social obligatorio desde 1938. Motivo que restauraba el equilibrio de fuerzas entre las tres mujeres fuertes del régimen: la «margarita» Urraca Pastor, la jonsista Sanz Bachiller, como responsable del Auxilio Social, y la dirigente de Sección Femenina de FET-JONS, Pilar Primo de Rivera ${ }^{50}$.

Con la información recogida por los ocho grupos de agentes divididos por sexos, se llegaron a elaborar más de 1.000 .000 de informes con información sustanciosa sobre los movimientos de población y las personas más significadas políticamente de cada localidad. Cifra similar a los registros de la Sección Político Social del Ministerio de Gobernación en Salamanca, con los que buena parte de la población civil de la España republicana quedaba fichada para el Nuevo Régimen ${ }^{51}$.

Sabemos que las quintacolumnistas colaboraron en los servicios documentales del Ejército y la Junta Técnica del Estado por dos razones. La primera explicación va unida a la carga sexual del espionaje o la clásica ecuación de «la cama como confesionario», que concebía a las señoritas socializadas en los felices años 20, frecuentadoras de los cabarets de Madrid o la Barceloneta, como facilitadoras de la información extraída a los milicianos. La segunda causa se debe a la irrupción de las conocidas «modernas» en los oficios de cuello blanco, convirtiendo al secretariado o la telefonía en empleos feminizados e idóneos, por su manejo de conversaciones y papeles comprometedores, para las labores de espionaje ${ }^{52}$. Sin ir más lejos, la ya camisa vieja de Alcañiz, Rosa Bríos, «siempre tuvo la línea a disposición de la Organización», hasta su fusilamiento con 31 años, en marzo de $1937^{53}$.

\footnotetext{
49 RUIZ-BERDÚN, 2015.

${ }^{50}$ Sobre la competencia entre estas tres mujeres existen multitud de publicaciones, véase PRESTON, 2001.

${ }^{51}$ ESPINOSA y RODRÍGUEZ, 2015.

52 CAPEL MARTÍNEZ, 1986. BORDERÍAS MONDÉJAR, 1993. MANGINI, 2001. LLONA GONZÁLEZ, 2002. LUENGO LÓPEZ, 2009.

${ }^{53}$ SÁNCHEZ BLANCO, 2016: 79.
} 
Que la mano de obra existente en la oficina tradicionalista de «Nacho Enea», en San Juan de Luz, como en la del Fichero de Cataluña de San Sebastián, o la Delegación para la Recuperación de Documentos en Salamanca, estuviera abastecida por un buen número de jóvenes margaritas o falangistas, no es casualidad. Responde igualmente a ese rol de género por el que se otorgaba a las mujeres una especial aptitud para desempeñar «labores de primor» de forma abnegada, gratuita y silenciosa, consecuencia de su empeño misional como viudas, hijas de caídos, o prestatarias del Servicio Social obligatorio entre solteras de 17 a 35 años $^{54}$.

Así lo expresaban las Mujeres al Servicio de España, asociación creada en 1936 por Emilia de Tudela Bonell y Victoria Fernández Manzano en Lugo, y que se dedicó fundamentalmente a la confección de ropa para los soldados franquistas:

Con orgullo podemos decir que damos nuestro trabajo sin exigir ni esperar nada. Nuestro trabajo queda cumplidamente pagado con la tranquilidad de nuestra conciencia. Entre las miles de mujeres que afiliadas a nuestra organización, trabajan sin descanso, encuéntranse algunas que perdieron en las luchas políticas a seres muy queridos; otras cuyos familiares perdieron los destinos por sus ideas católicas en época en que forzosamente (decían) España no había de serlo; muchas que por la crisis de trabajo impuesta por personas que se dan el título de padres del obrero, están sin comer, y unidas todas, cogidas fuertemente unas a otras, formando ese muro de contención de aguas inmundas que quiere destruir a nuestra Patria ${ }^{55}$.

La patriótica tarea de estas «cristeras españolas» estaba tan sexualizada que dibujaron una Betty Boop costurera y nacionalista, como símbolo de las integrantes del ropero. Una imagen de modernidad que, como las «madrinas de guerra» que escribían a los frentes para mantener la moral de la tropa, atrajo a miles de muchachas casaderas para infiltrarse voluntariamente en organizaciones prohibidas ${ }^{56}$.

Los rebeldes reclutaron colaboradoras en las principales ciudades de Francia. En París operaba la señora de Ojeda, enlace en el despacho de Quiñones de León, y las hermanas Carme y Soler i Ferran para la oficina de información de los rebeldes. En Marsella, la noruega Adi Enberg, hija del cónsul de Dinamarca en Barcelona y pareja de Josep Pla durante la guerra, fue la secretaria de la oficina de información de Bertrán i Musitu ${ }^{57}$. Finalmente, en Perpignan, nodo a través del cual se efectuaba el contrabando de armas y el paso clandestino de personas,

\footnotetext{
${ }^{54}$ REBOLLO MESAS, 2003. DÍEZ FUENTES, 1998.

${ }_{55} \mathrm{CDMH}$, Incorporados, caja 754, exp. 3. Uno de los escasos trabajos en Galicia es el de MARTINS RODRÍGUEZ, 2012.

${ }^{56}$ DE RAMÓN y ORTIZ, 2003. CARABIAS ÁLVARO, 2003.

${ }^{57}$ GUIXÁ, 2014: 162-175, 393.
} 
se coló la secretaria y amante del anarquista Giuseppe Pasotti, Juanita Mir Sánchez, que viajaba a Barcelona para recoger las cartas enviadas desde Italia, copiaba las más interesantes para la Policía Política, «al tiempo que daba los nombres de los voluntarios que cruzaban la frontera procedentes de Francia ${ }^{58}$.

Aunque el Servicio de Prensa y Propaganda carlista disponía de otras oficinas en San Sebastián, Burgos, Zaragoza y la Casa de las Conchas en Salamanca, que empleaban también a «margaritas», Ricardo Ollaquindía describió la oficiosa embajada franquista «Nacho Enea» como un despacho de agentes de enlace, que funcionaba desde 1935 y que se ocupó en plena guerra de la censura de correspondencia y de la adquisición de prensa extranjera ${ }^{59}$.

La labor de «inteligencia» desarrollada en el País Vasco francés y la capital parisina era habitual desde los años 20. Antes de que acabara el verano de 1936, se acusó al conde de los Andes, el duque de Saint Cyr y Matilde Jiménez, la amante de Juan March, de actividades conspirativas desde Biarritz. Uno de los primeros centros improvisados de la conspiración franquista se situó en la villa La Ferme en Bayona, cuya propietaria era la condesa francesa de Gironde. Parece ser que ésta se asustó por la reunión celebrada en su casa con Von Goss, agente de la Abwehr de Canaris, y sus servicios se transfirieron a Nacho Enea en agosto de 1936. Por tanto, a partir de esa fecha, la villa centralizó la actividad de los franquistas, separando la información del activismo armado, los servicios de propaganda y representación, cuando los carlistas quedaron relegados a un segundo plano.

El director de la villa hasta abril de 1938 fue Luis Martínez de Irujo, y su persona de confianza, Carmen Zappino Barcaiztegui, amiga íntima de la marquesa de Gironde, como miembros de la Junta de Señoras de Renovación Española, el partido monárquico alfonsino. La secretaria general se rodeó, a su vez, de otras mujeres que Irujo compensó con 2.000 francos para su mantenimiento. Entre ellas se encontraban la auxiliar, María Razpide y Moret, madrileña de 49 años, incorporada en septiembre de 1937; María Luisa L. de Rolland y María Rodríguez de la Encina, mientras que el importantísimo archivo y fichero clasificador fue confiado a María de la Concepción Angulo. Finalmente, cuando tras el verano de 1937 el dispositivo se trasladó al Hotel Plaza de Biarritz, la organización corrió a cargo de Dolores Angenes y Enriqueta Aza, hallándose en la habitación de Dolores, delegada de la Cruz Roja Cubana, la documentación que se logró sacar de la anterior sede del espionaje franquista ${ }^{60}$.

${ }^{58}$ NÚÑEZ DE PRADO, 1992: 146. BARRUSO BARÉS, 2008: 82, 367. HERBERG y ROS, 2006: 60, 67.

59 OLLAQUINDÍA, 1995.

${ }^{60}$ Enlace Nacho Enea, 40004-Haberes Personal N.E., 1937, 40003-Personal, situación en Francia y 40005-Pases personal, CDMH, Incorporados, caja 1479, 1; caja 1.480, 1 у caja $1.481,1$. 
Ya en el invierno de 1936, recién ocupado San Sebastián pero con el frente vasco activo, gran número de contactos pululaban en torno a Nacho Enea. El colaboracionismo pro-fascista contaba allí con Margarita Alzola Echeverría, que actuaba con un agente expulsado de Francia, Ruiz del Portal, así como con un grupo de chicas jóvenes dirigido por un empleado de la empresa Echevarría, S.A., que perseguían a los refugiados en Bilbao o Santander ${ }^{61}$.

A finales de año, el comisario de policía de Hendaya acusó al propietario de la villa, Ínigo Bernoville, de organizar desde allí el tráfico de moneda con España y las actividades de espionaje. Comenzaron las redadas y sus funciones se desplazaron a Biarritz en marzo de 1937. A partir de entonces, los servicios de información fueron controlados por José Bertrán i Musitu y Francisco Moreno, conde de los Andes, que organizaron el SIFNE en relación directa con la Secretaría General del Estado en Salamanca. De ese modo, Nacho Enea se encargaría de las actividades legales y el SIFNE de las clandestinas ${ }^{62}$.

Fue en septiembre de 1937 cuando, tras la frustrada ocupación de los submarinos republicanos por el comandante del Bidasoa Julián Troncoso, las autoridades francesas aprovecharon para expulsar del país a 40 personas y, entre ellos, cuatro mujeres: la manchega Consuelo Palacios, de 34 años; la catalana Sara Pumareda, de 26 años y perteneciente a la organización de Tamburini; Margarita de Pedroso, de su misma edad, nacida en Bruselas y adscrita a Nacho Enea, como la guipuzcoana Carmen Zappino, ocupada del dinero recaudado por esta oficina y la correspondencia de los agentes franquistas, que finalmente no salió ${ }^{63}$.

\section{ABRIL DE 1937: «SEÑORITAS» AL SERVICIO DE LA INTELIGENCIA MILITAR}

La segunda sede de los servicios de inteligencia franquista se encontraba en San Sebastián. Según la memoria firmada en 1938 por el Teniente Auditor, José Parellada, fue otro local de la Junta de Guerra Carlista, como lo había sido Nacho Enea en origen, el que albergó lo que habría de denominarse como «Fichero de Cataluña». Al igual que en San Juan de Luz, el Marqués de Alella se encargaba allí de leer la prensa republicana y pegar recortes sobre la actuación de los antifascistas en Barcelona. Fue precisamente Parellada quien, a finales de enero de 1937, le sugirió la idea de confeccionar un fichero con los mismos, «en orden a la consulta y subsiguiente sanción el día de mañana a los delincuentes $»^{64}$.

\footnotetext{
${ }^{61}$ BARRUSO BARÉS, 2008: 77-83, 149.

62 «El asunto del espionaje en Marsella», La Vanguardia (19-8-1937): 5.

${ }^{63}$ Informe del DEDIDE sobre espionaje en Francia (enero, 1938), AGA, Ministerio de Asuntos Exteriores, Archivo de Barcelona, RE 98, caja 5, pliego 9.

${ }^{64}$ Memoria sobre el Fichero de Cataluña, CDMH, DNSD, Presidencia, caja 94, 3.
} 
Al constituirse la Comisión de Asuntos Carlistas de Cataluña en Donosti, el fichero se trasladaría allí el 15 de marzo, con los testimonios de los tránsfugas que, al llegar a zona nacionalista, relataban los «desmanes» ocurridos en sus respectivas poblaciones y distinguían a los agentes revolucionarios (rojos) de los derechistas (blancos). En un año pasaron alrededor de 3.800 informantes, elaborándose varias fichas duplicadas a partir de cada uno. Al comprobarse su utilidad, el fichero fue reclamado por diversas instancias (gobierno, policía, juzgados...) y se decidió pasar su custodia a la jurisdicción del Ejército de Ocupación.

La vocación de servir a la justicia militar y, especialmente, a la represión de la capital republicana, hizo que el destino final elegido para el Fichero de Cataluña, como el de Talavera, fuese la Auditoría de Guerra Nacional en Zaragoza, evitando la competencia entre partidos tras el Decreto de Unificación de FETJONS. El Requeté catalán cedió, pues, su propiedad y financió una nueva copia del fichero demandada por el ministro Martínez Anido para Valladolid. Fichas triplicadas que obligaron a su supervisor, el comerciante barcelonés José Torras Riera, «a utilizar un equipo de diez entusiastas señoritas» ${ }^{65}$.

Ellas confeccionaron también registros complementarios con estadísticas de todos los pueblos de Cataluña, sus centros marxistas, las comisiones de presos y presentados al servicio militar, o los reclutas del Cuartel de Loyola. Un panorama que, en febrero de 1938, arrojaba ya un total de 180.000 asientos, y un $80 \%$ del total regional, por el esfuerzo material y humano de 26 hombres y 14 mujeres, la mitad de ellas hermanas entre sí:

Personal de ambos sexos, todo lo cual rivaliza en celo y amor al trabajo, siendo de notar que no solo trabaja desinteresadamente [...] simpáticas señoritas que cumpliendo deberes de Auxilio Social, han venido a última hora a edificarnos con su celo juvenil. Día tras día, con espíritu verdaderamente abnegado, sin respetar a veces las fiestas, han venido a la oficina trabajando como obreros manuales muchos que en Barcelona eran verdaderos potentados ${ }^{66}$.

El tercer y último pilar de esos servicios de espionaje sería la Delegación Nacional de Recuperación de Documentos (DERD) establecida en Salamanca, nacida en la atmósfera de derrumbe del frente norte el 31 de julio de 1937, como nueva base de los servicios de información y armazón primigenio del llamado Archivo de Salamanca. Dirigida por Marcelino Ulibarri, su misión fue recoger la documentación relacionada con las actividades «marxistas»y

65 «Srtas. Elvira Coto Argemi, Amelia Brugarolas Rocamora, María Montserrat Mallorens Puiggali, María Concepción Secanell Clua, Mercedes Secanell Clua, Montserrat Dura Bellido, Rosa Torras Trías, Asunción Portabella Fábrega, María Teresa Portabella Fábrega, María Engracia Olivella Canals, Josefina Olivella Canals, María Butiña Vila, Teresa Hostench Butiña y María del Carmen Dosset Puigmartí».

${ }^{66}$ Memoria sobre el Fichero de Cataluña, CDMH, DNSD, Presidencia, caja 94, 3. 
proporcionar información sobre los defensores de la legalidad republicana. De este modo, la Auditoría del Ejército de Ocupación que disponía de los ficheros de Cataluña, del SIFNE y de Orden Público en Fuenterrabía, se hacía también con el valioso acervo depositado en la ciudad del Tormes, como pieza clave de la jurisdicción militar de los sublevados ${ }^{67}$.

¿Qué papel desempeñaron las mujeres en ese conglomerado? Una vez más las encontramos en los estadillos semanales de personal, colaborando con el Fichero de Recuperación de Salamanca, dependiente de la Auditoría de Guerra. Sabemos, por ejemplo, que en la semana del 12 al 18 de noviembre de 1937, «6 chicas» elaboraban 400 fichas diarias. Es decir, trabajando seis días por semana y librando sólo los domingos, un equipo como éste arrojaba un total de 2.385 fichas, 400 por persona, dedicando tres jornadas completas a confeccionarlas y ocupando a una compañera otras tres para «intercalarlas» ${ }^{68}$.

Pero no era ésa la única actividad de las mujeres colaboracionistas. Para que los guardias civiles en la Clerecía y los militares en el Diocesano pudieran trabajar a pleno rendimiento en el procesado de la documentación incautada, las monjas del manicomio cercano a la DERD, llevaban cada día el almuerzo a sus trabajadores.... De ese modo se colonizó todo el espacio público, militarizado y convertido en Cuartel General del Generalísimo ${ }^{69}$. ¿Quiénes se encargarían de alimentar y lavar los uniformes de tanto hombre en campaña? ¿Quiénes de entretener sus días en la retaguardia? Las mujeres de orden y las prostitutas del Barrio Chino, a las que los estudiantes militarizados traían de su cuarentena los «lunes de aguas» tras la Semana Santa.

Acabada ya la guerra en el «tercer año triunfal», las oficinas madrileñas de la DERD realizaron un ajuste de su personal, gracias al cual Rosario Herrero Castillo, secretaria del coronel y «mecanógrafa a su inmediato servicio», fue reclamada por la Sección de Justicia, donde todos los auxiliares eran mujeres cedidas por la Auditoría de Guerra del Ejército de Ocupación, «cuya permanencia no es muy segura por estar pendiente de que se les compute para Servicio Social» ${ }^{70}$.

\section{Abril de 1939: un ajuste de cuentas}

Con la victoria franquista, buena parte de las movilizadas y caídas de primera hora serían condecoradas con la «Y» de oro de Sección Femenina por sus

\footnotetext{
${ }^{67}$ ESPINOSA y RODRÍGUEZ, 2015. GONZÁLEZ QUINTANA, 2005; 1994.

${ }_{68} \mathrm{CDMH}, \mathrm{DNSD}$, Secretaría, Recuperación, caja 37, 3.

${ }^{69}$ CUESTA BUSTILLO, 1997. DE PRADO HERRERA, 2012. SERRAT BONASTRE, 2014. También el folleto editado sobre Salamanca en guerra: CDMH, FA-01239.

${ }^{70}$ Correspondencia entre la Oficina Central y la de Madrid, CDMH, DNSD, Secretaría, exp. 46.
}

Hispania, 2020, vol. LXXX, n. ${ }^{\circ}$ 265, mayo-agosto, págs. 531-561, ISSN: 0018-2141, e-ISSN: 1988-8368 https://doi.org/10.3989/hispania.2020.015 
méritos de guerra. Ése sería el caso de Carmen Tronchoni Soria, de 22 años. Como otras muchas telefonistas, su labor consistió en interceptar las comunicaciones para informar a sus camaradas en Valencia y colaborar con el Socorro Blanco, convirtiéndose en «uno de los elementos más activos de la Quinta Columna en aquella capital» hasta febrero de $1937^{71}$.

Pastor Petit la compara con Lina Odena y la adscribe a la organización clandestina del SIFNE en la costa mediterránea, ya que su trabajo se extendió al espionaje de los brigadistas que acudían al bar Vodka, para informar después a los sublevados de sus planes y preservar la vida de los perseguidos, buscándoles refugio en la capital del Turia y documentación falsa para pasarse a la zona sublevada. Dos infiltrados del SIM republicano, Ismael Villaplana e Inés Jiménez Lumbreras, terminaron delatándola y actuaron como testigos de cargo ante el Tribunal de Alta Traición y Espionaje de Barcelona.

Acusada de actividades fascistas y preparación de planos con posiciones militares, Tronchoni sería fusilada finalmente en Montjuich el 29 de marzo de 1938, junto a otras espías que no consiguieron el canje. Tal sería el caso, meses más tarde, de María Mira Calderón, enlace del barón Von Noellendorp Benoist, o las margaritas del Grupo Villalta caídas el 11 de agosto: Rosa Fortuny, Carmen Vidal Rovira, Catalina Viader Fors, María Luisa Gil Galvera, Joaquina Sot Delclòs y su prima, Sara Jordá, cuyos méritos glosaron: «Confidencias, informes, fotografías, planos, cartas... iiTodo, todo por España!! Y todo, todo pasó de sus manos a las de los enlaces de Franco»» ${ }^{72}$.

Si utilizamos como estudio de caso Barcelona, ciudad donde fueron ejecutadas todas estas mujeres, observamos que según los listados de la Delegación Provincial de la Hermandad de Cautivos por España, el promedio de presos políticos allí durante la guerra fue de 3.504 personas, habiendo entre ellos 367 mujeres, el 10,47\% ${ }^{73}$.

Desestimando los casos de imputadas cuyo único motivo de detención era escribir a un novio falangista, ser enfermeras religiosas, porteras de edificios donde estaban instaladas las patrullas de control, o mostrar una actitud victimista, pero sin una implicación personal en la red clandestina, pasaríamos a aquellas mujeres que informaron sobre la organización del Socorro Blanco o las viudas del Grupo Villalta, así como las derechistas que intentaron pasar la frontera, emboscarse y ser miembros activos de la quinta columna en Barcelona.

${ }^{71}$ SÁNCHEZ BLANCO, 2016: 79, 117.

72 SÁNCHEZ BLANCO, 2016: 134. PASTOR PETIT, 2006: 180.

${ }^{73} \mathrm{CDMH}$, Causa General de Barcelona, Gerona y Baleares, Pieza Cuatro, Checas, caja 1633, exp. 1. 
CUADRo 1. Causas instruidas en Barcelona por juzgados republicanos, 1936-1939

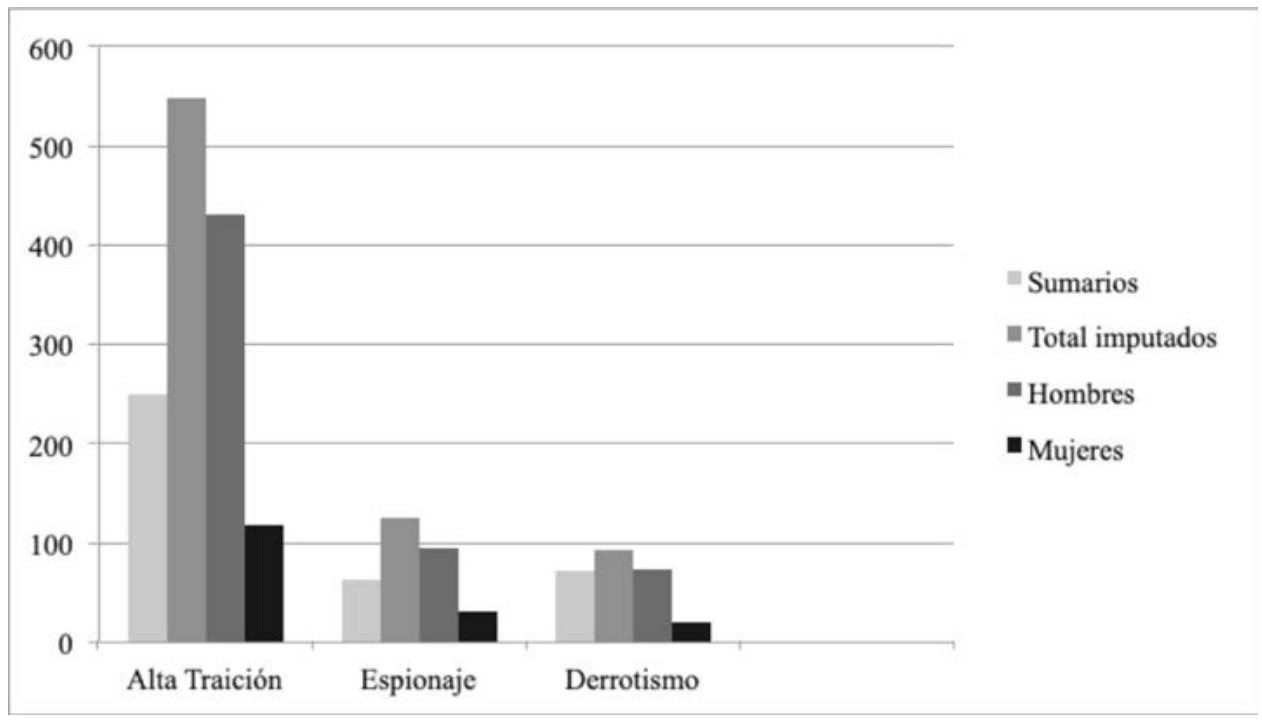

Elaboración propia. Fuente: CDMH, Causa General de Barcelona, caja1637, exp.45.

En la Causa General de aquella provincia aparecen los/as procesados/as por los tribunales de espionaje y alta traición $\mathrm{n}^{\circ}{ }^{\mathrm{o}} 1,2,3$ y 4 , así como por los juzgados de instrucción, tribunales populares y especiales de guardia. En la relación más completa aparecen 140 causas instruidas por delitos político sociales entre 1937 y 1938, y en las de alta traición encontramos 548 personas imputadas, 117 de ellas mujeres, el $21^{\prime} 4 \%$. Entre las causas de espionaje hay 31 , el $24^{\prime} 8 \%$, siendo una de ellas, María Luisa Laurenci, juzgada por falsificación de pasaportes. En las de derrotismo serían el $21^{\prime} 5 \%$, y en las de deserción apenas tres mujeres, no apareciendo en los juicios más violentos por terrorismo, asesinato o sabotaje.

Finalmente, las sentencias de esas causas sirven para comprender el tipo de actividades femeninas en la quinta columna. Ahí vemos que sólo un 10'8\% fueron penadas por alta traición, un $11^{\prime} 8 \%$ en las de espionaje y el $366^{\prime} 2 \%$ por derrotismo, menos doloso, que predominó sobre cualquier otro delito ${ }^{74}$.

Convertir las vidas de estas mujeres en modelo de beatitud, como se hizo con las cristeras, en lugar de reconocer el valor político de sus actos, equivale a negar su capacidad de agencia histórica. Aunque admitiéramos que el móvil meramente asistencial y piadoso superaba al proselitismo y la propaganda, o los actos ilegales de ocultar armas, servir de enlaces o suministrar documentación

\footnotetext{
${ }^{74}$ CDMH, Causa General de Barcelona, Pieza cinco, Justicia Roja, caja 1637, exp. 45.
} 
falsa... «lo personal (también) es político» ${ }^{75}$. Aun reconociendo buena parte de las atrocidades que se cometieron con ellas, en la mayoría de los casos ni fueron «engañadas», ni meras y dolientes pasionarias, lo que supondría condenarlas a una eterna minoría de edad ${ }^{76}$.

CuAdro 2. Sentencias de las causas instruidas por los tribunales de Barcelona, 1936-1939

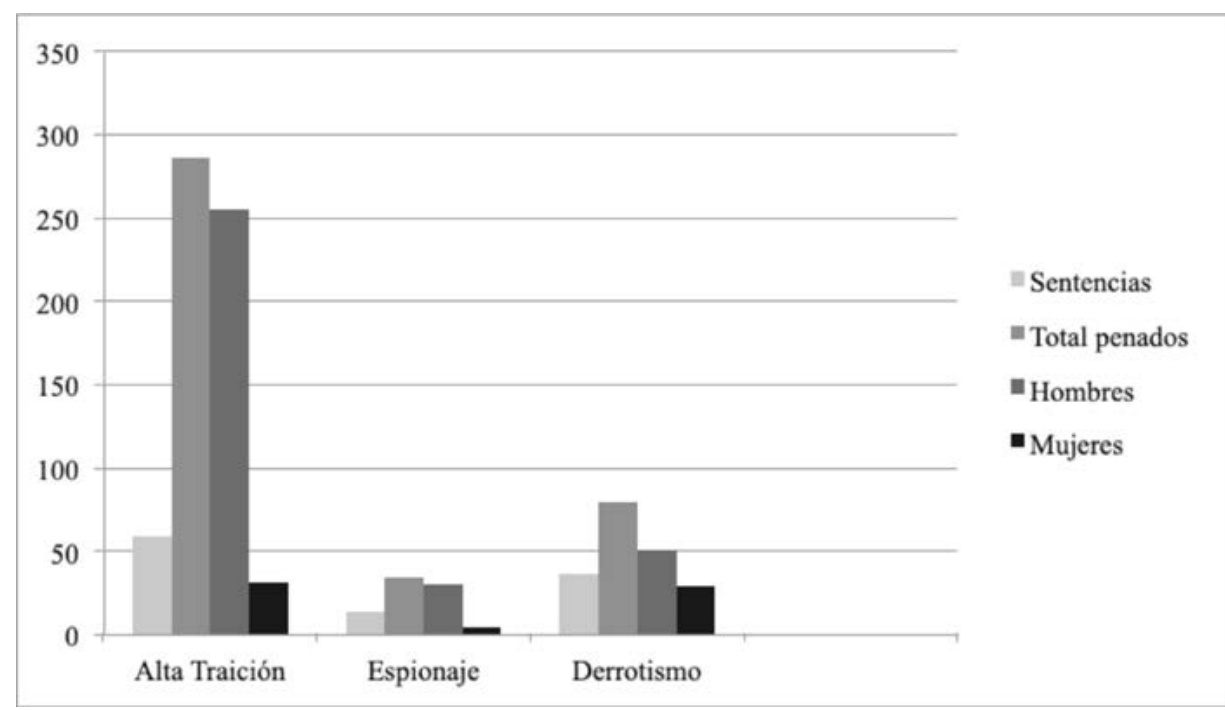

Elaboración propia. Fuente: CDMH, Causa General de Barcelona, caja1637, exp. 45.

\section{1-1944: La División AzUl en la SEgunda Guerra Mundial}

Durante los años en que más de un centenar de mujeres corrientes se jugaron la vida intentando socavar la dictadura desde las agrupaciones guerrilleras, otras muchas se entregaron a la delación ${ }^{77}$. En la cima, las señoras de Franco aplaudían la pérdida de sus derechos, enarbolando el mensaje de la reacción tradicionalista como señuelo de la violencia simbólica que se cernía sobre ellas ${ }^{78}$.

\footnotetext{
${ }^{75}$ MILLET, 1969.

76 RUIZ FRANCO, 2007. BLASCO HERRANZ, 2008.

$77 \mathrm{https}$ //diagonalperiodico.net/blogs/imanol/mujeres-la-guerrilla-2a-parte.html [consultado 27/02/2019].

${ }^{78}$ BOURDIEU, 2000: 49-59.
} 
Aunque el hambre eclipsó la Victoria y las ganas de paz, el inicio de la guerra europea fue vivido también con intensidad en España, desde la confianza en la superioridad de las potencias fascistas. Según el testimonio de María Gracia Fernández, regidora de la Hermandad de la Ciudad y del Campo en Almería, fue entonces precisamente cuando se fortaleció la imagen de Franco:

Mis hermanos se querían ir a la División Azul [...] Casi todos los hijos de los que había matado la guerra, todos se alistaron porque, claro... nosotros era más bien la parte de Alemania... Hitler también quiso pues... vamos, que Franco dejara pasar a las tropas y todo eso, y Franco dijo que no [...] tuvo a Hitler esperándolo tres horas, y el otro estaba... acostumbrado a ver, ordenar, mandar y saber... Entonces Franco le dijo que España no estaba en situación de meterse en otra guerra porque tenía un pueblo hambriento, que tampoco se fiaba porque había todavía muchos rojos y que... que no lo creía conveniente... Es que en un principio parecía que Alemania se tragaba al mundo y el gallego tenía muy buen ojo ${ }^{79}$.

Aunque rechazara la proposición de Ribbentrop de declarar la guerra directa a Rusia, en junio de 1941 «el gallego» decidió el envío de voluntarios para contribuir a esa otra cruzada contra el comunismo internacional. Tras las disquisiciones sobre mandar un ejército profesional, o una división española para integrarse dentro del ejército alemán, se llegó a una solución intermedia: se crearía una división compuesta exclusivamente de 15.000 voluntarios, pero comandada por oficiales como el general Agustín Muñoz Grandes ${ }^{80}$.

El mismo día en que partió de Madrid la primera expedición, el 15 de julio de 1941, se dieron instrucciones a las provincias sobre la movilización de las españolas en tres tipos de servicios: los de vanguardia, retaguardia o industria militar. Las falangistas se mostraban preparadas para todo, pero al integrarse la División Azul como 250 división de la Wehrmacht, los alemanes se hicieron cargo de todas las tareas de intendencia y la labor de SF se limitó a la recogida de donativos para preparar los «aguinaldos del soldado».

Los problemas de competencias femeninas volvieron a aflorar entonces, cuando las «Damas Auxiliares de Sanidad», dependientes exclusivamente del ejército y bajo las órdenes de Mariano Gómez Ulla, no fueron en calidad de enfermeras falangistas, tal y como se decretó al final de la Guerra Civil. Este hecho hizo que sólo un pequeño grupo de las afiliadas a SF (84 para un total de seis expediciones) pudieran acudir al frente ruso, entre el 24 de agosto de 1941 y el 12 de agosto de 1943. El primer grupo de 34 miembros fue el más entusiasta y voluminoso pero, sólo un mes y medio después de entrar en combate,

79 Entrevista a María Gracia Fernández Ruiz (Almería, 23-8-2002). Sobre la subjetividad de los voluntarios, NÚÑ̃Z SEIXAS, 2016, y sobre la intencionalidad real de Franco de inmiscuir a España en la guerra: PRESTON, 2000 y CAZORLA SÁNCHEZ, 2000: 60-63.

${ }^{80}$ SUÁREZ FERNÁNDEZ, 1993: 139-162. AGUSTÍ ROCA, 2003. 
empezó a detectarse la dureza y la decepción por los más de 400 muertos y 1.100 heridos. Un hecho que al cumplirse un año, en agosto de 1942, conminó a la SF a organizar un equipo de 200 madrinas de guerra por provincia para escribir y mantener el ánimo de, al menos, uno o dos combatientes.

La debacle de Alemania en 1943, la primera conciencia sobre el holocausto judío y el destino de los sefarditas españoles, pero sobre todo la noción de que Alemania ya no se prefiguraba como favorita para ganar la contienda, hicieron que en septiembre se vislumbrara el fin de la División Azul y el distanciamiento de Hitler, tras las visitas cursadas por Pilar Primo de Rivera y sus máximas colaboradoras. Las campañas de propaganda en sus revistas y de recogida de fondos para los voluntarios no habían decaído, pero el 1 de octubre cambió la «no beligerancia» de España por una postura de «neutralidad vigilante», haciendo que el embajador en Berlín comunicara a Ribbentrop la retirada de los/ las divisionarios, último contacto de las españolas con un frente de guerra ${ }^{81}$.

Tras la caída de Mussolini sólo quedaba rezar. La propia Delegación Nacional de Sección Femenina intensificó las circulares pidiendo a las afiliadas realizar sinceras oraciones por la paz, demostrando el miedo que flotaba en el ambiente por las consecuencias que para la dictadura podía tener la derrota nazi, pese a la confianza depositada en el Caudillo ${ }^{82}$. El giro neutralista del régimen a partir de 1943 sería liderado por el ministro de Exteriores, Francisco Gómez Jordana, quien vino a sustituir al filogermano Ramón Serrano Suñer, desplegando una operación propagandística de recatolización que colocaba a Franco como Homo misus a deu, "Caudillo por la Gracia de Dios», y a España como «centinela de Occidente». Rodrigo Vivar Téllez, nombrado gobernador civil de Vizcaya tras los sucesos de Begoña de 1942, y vicesecretario general del Movimiento en 1945, apeló entonces a la misión evangelizadora que deparaba a la Sección Femenina. Y como cierre de su IX Consejo Nacional celebrado en Bilbao, les pidió que suplicaran a la Virgen calmar «las pasiones de los hombres [...] de un régimen que es incapaz de evitar guerras como la actual, que ha convertido en montones de escombros y ruinas las maravillas de una cultura dos veces milenaria, que está sembrando de cadáveres todas las latitudes y que ha abierto unos abismos de odio y de rencor tan insondables $\rangle^{83}$.

${ }^{81}$ MORANT I ARIÑO, 2014. WINGEATE PIKE, 2010: 229-230. Sobre la información que llegó a España en junio de 1944 sobre los campos de exterminio nazis: AGA, Ministerio de Asuntos Exteriores, 82, 05247, 005 «Protocolos de Auschwitz». (Tres informes de prisioneros húngaros fugados y difundidos desde Suiza, que llegaron al ministro José Félix de Lequerica a través de Ángel Sanz Briz, representante de la Legación española en Budapest).

${ }_{82}$ A todos los mandos jerárquicos e instructoras de la Sección Femenina de Falange, AGA, Circulares de la Delegación Nacional. Circular 208 (11-VIII-1943), Circular 2, serie A $(1-\mathrm{V}-1945)$ y $3-8-1945$.

83 «Discursos del IX Consejo Nacional de SF, celebrado en Bilbao (1945), a cargo de Rodrigo Vivar Téllez», Y, 86 (marzo, 1945). 
Mujeres piadosas rezando por los hombres pasionales y beligerantes... Cuando toda Europa se preparaba para la desmovilización femenina de los frentes de batalla, España se replegaba nuevamente hacia el interior y daba la vuelta, como un calcetín, a una década de conquista de derechos y espacios en materia de género. Tras la ocupación de las tribunas y las barricadas, las españolas volverían a los bancos de las iglesias. Si el Fuero del Trabajo de 1938 se encargó de comprimir, como una faja, a quienes se habían empleado a fondo como telefonistas, secretarias, archiveras y enlaces de la quinta columna, su buen hacer sería recompensado con pensiones de guerra, estancos, cuotas de oposición a la función pública, así como unas condecoraciones menos visibles que las de los hombres del coronel José Ungría, que continuaron su labor en la temida Delegación de Información e Investigación de FET-JONS.

\section{Conclusión}

Las españolas que habían trabajado en oficios de cuello blanco para los sublevados vestirían en adelante el azul mahón de la Falange. Separadas de la actividad paramilitar e imbuidas de un folklorismo menos peligroso, pareció que nunca las mujeres de derechas hubieran estado vinculadas a la acción bélica y la violencia política. Se eclipsaba así una genealogía de combatividad católica femenina iniciada por las cristeras y cuyo colofón fue la División Azul.

Más allá de las viudas e hijas de caídos que colaboraron con la delación y represión franquista, esta investigación trata de entroncar a las quintacolumnistas de la Guerra Civil con los/as Desk murderers ('criminales de escritorio'), como los describiera Hannah Arendt a raíz del juicio de Eichmann. Porque si la participación directa de las españolas en las acciones físicamente violentas desencadenadas desde la revolución de 1934 fue minoritaria, no puede decirse lo mismo del tráfico de armas ni, sobre todo, los engranajes institucionales para el ejercicio de esa violencia. Tanto los tribunales republicanos como los órganos de inteligencia de ambos bandos insisten en demostrar la fuerte presencia de mujeres jóvenes en todas las facetas de los servicios de información: espionaje, falsificación, criptografía, gestión documental y archivo de datos, que podrían decidir sobre la vida o la muerte de miles de personas ${ }^{84}$.

\section{Bibliogr AFÍA}

Aguado Higón, Ana M. y Ortega López, Teresa M. (coords.), Feminismos y antifeminismos: culturas politicas e identidades de género en la España del siglo XX, Valencia/Granada, Universitat de València, 2011.

\footnotetext{
${ }^{84}$ VON SALDERN, 1994.
}

Hispania, 2020, vol. LXXX, n. ${ }^{\circ} 265$, mayo-agosto, págs. 531-561, ISSN: 0018-2141, e-ISSN: 1988-8368 https://doi.org/10.3989/hispania.2020.015 
Agustí Roca, Carme, Rússia és culpable!: Memòria i record de la División Azul, Barcelona, Pagès, 2003.

Alcocer Badenas, Santos, La Quinta Columna, Madrid, G. del Toro, 1976.

Álvarez-Pimentel, Ricardo José, «Guerra Fría, Guerra Cristera, Guerreras Católicas: el conservadurismo y feminismo católico de la Juventud Católica Femenina Mexicana (JCFM), 1926-1939», en Nuevo Mundo Mundos Nuevos (París, 2017) [en línea], Colloques, URL: http://journals.openedition.org/nuevomundo/71299 [consultado el 20/0372019]. doi: 10.4000/nuevomundo.71299.

Arce Pinedo, Rebeca, Dios, patria y hogar: la construcción social de la mujer espanola por el catolicismo y las derechas en el primer tercio del siglo $X X$, Santander, Universidad de Cantabria, 2008.

Barrera López, Begoña, La Sección Femenina, 1934-1977. Historia de una tutela emocional, Madrid, Alianza, 2019.

Barruso Barés, Pedro, Información, diplomacia y espionaje. La Guerra Civil española en el sur de Francia (1936-1940), San Sebastián, Hiria, 2008.

Belda Plans, Juan, Grandes personajes del Siglo de Oro español, Madrid, Palabra, 2013.

Bertrán i Musitu, José, Experiencias en los Servicios de Información del Nordeste de España (SIFNE) durante la guerra, Madrid, Espasa-Calpe, 1940.

Blasco Herranz, Inmaculada, Paradojas de la Ortodoxia. Política de masas y militancia católica femenina en España (1919-1939), Zaragoza, Publicaciones Universidad de Zaragoza, 2003.

Blasco Herranz, Inmaculada, «Más poderoso que el amor: género, piedad y política en el movimiento católico español», Pasado y Memoria, 7 (Alicante, 2008): 79-100.

Borderías Mondéjar, Cristina, Entre líneas. Trabajo e identidad femenina en la España Contemporánea: la Compañía Telefónica (1924-1980), Barcelona, Icaria, 1993.

Bourdieu, Pierre, La dominación masculina, Barcelona, Anagrama, 2000.

Bravo, Anna, In guerra senza armi. Storie di donne 1940-1945, Roma/Bari, Laterza, 1995.

Bunk, Brian D., Ghosts of Passion. Martyrdom, Gender, and the Origins of the Spanish Civil War, Durham, Duke University Press, 2007.

Capel Martínez, Rosa María, El trabajo y la educación de la mujer en España (19001930), Madrid, Instituto de la Mujer, 1986.

Carabias Álvaro, Mónica, Imágenes de una metáfora circunstancial: La mujer falangista como mujer moderna, Madrid, Universidad Complutense de Madrid, 2003.

Cazorla Sánchez, Antonio, Las políticas de la Victoria: la consolidación del Nuevo Estado franquista (1939-1953), Madrid, Marcial Pons, 2000.

Cervera Gil, Javier, Madrid en guerra. La ciudad clandestina, 1936-1939, Madrid, Alianza, 1998.

Cuesta Bustillo, Josefina, «La guerra civil y la militarización del espacio en Salamanca», Salamanca, Revista de Estudios, 40 (Salamanca, 1997): 403-429.

De la Cueva Merino, Julio, «El asalto de los cielos: una perspectiva comparada para la violencia anticlerical española de 1936», Ayer, 88/4 (Madrid, 2012): 51-74.

De la Cueva Merino, Julio, «Revolución, guerra y violencia contra la religión», en Fernando del Rey Reguillo y Manuel Álvarez Tardío (coords.), Políticas del odio: violencia y crisis en las democracias de entreguerras, Madrid, Tecnos, 2017: 387-430. 
De Prado Herrera, María Luz, La contribución popular a la financiación de la Guerra Civil: Salamanca, 1936-1939, Salamanca, Universidad de Salamanca, 2012.

De Ramón, Manuel y Ortiz, Carmen, Madrinas de Guerra: Cartas desde el frente, Madrid, Esfera de los Libros, 2003.

Del Moral Vargas, Marta, Acción colectiva femenina en Madrid (1909-1931), Santiago, Universidad de Santiago de Compostela, 2012.

Díez Fuentes, José Manuel, «El Servicio Social de la mujer, ¿un instrumento de formación y participación en las tareas del estado franquista, 1937-1959?», en Jornadas «Historia y Fuentes Orales», Ávila, Universidad Nacional de Educación a Distancia/Fundación Santa Teresa, 1998: 329-339.

Eley, Geoff, Un mundo que ganar. Historia de la izquierda en Europa, 1850-2000, Barcelona, Crítica, 2003.

Espinosa Romero, Jesús y Rodríguez López, Sofía, «El Archivo de Guerra Civil de Salamanca. De la Campaña a la Transición», en José C. Galende y Susana Cabezas (dirs.), Paseo documental por el Madrid de antaño, Madrid, Universidad Complutense de Madrid/Fundación Hospital San José Getafe, 2015: 131-155.

Fazio Fernández, Mariano, Francisco de Vitoria: Cristianismo y Modernidad, Buenos Aires, Ediciones Ciudad Argentina, 1998.

Fernández-Crehuet López, Federico y García López, Daniel J. (coords.), Derecho, memoria histórica y dictaduras, Granada, Comares, 2009.

Gahete Muñoz, Soraya, «Dora Maqueda. Su militancia en Falange Española», Asparkía, 27 (Castellón, 2015a): 163-180.

Gahete Muñoz, Soraya, «La Sección Femenina de Falange. Discursos y prácticas en Madrid», Arenal, 22/2 (Granada, 2015b): 389-411.

García Núñez, Vera L., «Las mujeres del Partido Acción Nacional: entre la beneficencia y la participación política (1939-1946)», en Nuevo Mundo Mundos Nuevos (París, 2017) [en línea], Colloques, URL: http://journals.openedition.org/nuevomundo/71307 [consultado el 20/03/2019]. doi: 10.4000/nuevomundo.71307.

Gil Pecharromán, Julio, "Sobre España inmortal, solo Dios». José María Albiñana y el Partido Nacionalista Español (1930-1937), Madrid, Universidad Nacional de Educación a Distancia, 2000.

Ginard Ferón, David, «Mujeres, juventud y activismo antifascista en la Europa mediterránea (1933-1945)», Ayer, 100/4 (Madrid, 2015): 97-121.

Gómez Bravo, Gutmaro, Geografía humana de la represión franquista. Del Golpe a la Guerra de ocupación (1936-1941), Madrid, Cátedra, 2017.

González Quintana, Antonio, «Fuentes para el estudio de la represión franquista en el Archivo Histórico Nacional, sección Guerra Civil», Espacio, Tiempo y Forma. Serie V, Historia Contemporánea, 7 (Madrid, 1994): 479-508.

González Quintana, Antonio, «Archivos para el estudio de la Guerra Civil Española», Archivamos: Boletín ACAL, $55-56$ (Salamanca, 2005): 41-45.

Guixá, Josep, Espías de Franco. Josep Pla y Francesc Cambó, Madrid, Fórcola, 2014. Heiberg, Morten y Ros Agudo, Manuel, La trama oculta de la Guerra Civil, Barcelona, Crítica, 2006.

Jaspe, Álvaro, «Ireland and Spain, 1931-1933. Divergent Republics», Journal of Irish Studies, 6 (Logroño, 2011): 8-20. 
Kaplan, Temma, «Conciencia femenina y acción colectiva: El caso de Barcelona, 1910-1918», en Historia y Género. Las mujeres en la Europa Moderna y Contemporánea, Valencia, Alfons el Magnànim, 1990: 267-295.

Kaplan, Temma, Ciudad roja, periodo azul. Los movimientos sociales en la Barcelona de Picasso (1888-1939), Barcelona, Península, 2002.

Lanero Taboas, Mónica, Una milicia de la justicia. La política judicial del franquismo (1936-1945), Madrid, Centro de Estudios Constitucionales, 1996.

Llona González, Miren, Entre señorita y garçonne. Historia oral de las mujeres bilbaínas de clase media (1919-1939), Málaga, Atenea, 2002.

López Martínez, Mario, «La Resistencia civil en Italia: su historia a debate», Desafíos, 24/2 (Bogotá, 2012): 17-44.

Lowe, Sid, The Juventud of Accion popular and the 'failure' of 'fascism' in Spain, 1932-1936, tesis doctoral inédita, University of Sheffield, 2000. [Publicado en 2010 con otro título en Brighton por Sussex Academic Press].

Luengo López, Jordi, Ocios y gozos de la mujer moderna, Málaga, Atenea, 2009.

Mangini, Shirley, Las Modernas de Madrid, Barcelona, Península, 2001.

Martins Rodríguez, M. ${ }^{\text {a }}$ Victoria, A regresión franquista. A muller o primeiro franquismo. Sección Feminina en Ponteareas (1936-1955), Vigo, Universidad de Vigo, 2012.

Mazower, Mark, La Europa Negra, Barcelona, Ediciones B, 2001.

Miller, Barbara, «The Role of Women in the Mexican Cristero Rebellion: Las Señoras y Las Religiosas», The Americas, 40/3 (Cambridge, 1984): 303-323. doi: 10.2307/981116.

Millet, Kate, Política Sexual, Madrid, Cátedra, 1995 [1969].

Morant i Ariño, Toni, Mujeres para una «Nueva Europa»: las relaciones y visitas entre la Sección Femenina y las organizaciones femeninas nazis, tesis doctoral inédita, Universitat de València, 2014.

Morant i Ariño, Toni, «Las mujeres que también fueron fascistas. Los primeros años de la Sección Femenina de Falange en una mirada transnacional», Historia del Presente, 32 (Madrid, 2018): 11-26.

Núñez de Prado y Clavell, Sara, «Las quintas columnas en la guerra civil española», Anuario del Departamento de Historia, 1 (Madrid, 1989): 223-232.

Núñez de Prado y Clavell, Sara, Servicios de información y propaganda en la Guerra Civil española, 1936-1939, tesis doctoral inédita, Universidad Complutense de Madrid, 1992.

Núñez Díaz-Balart, Mirta, «La ira anticlerical de mayo de 1931. Religión, política y propaganda», Cahiers de civilisation espagnole contemporaine, 18 (París, 2017) [en línea], consultado el 6 de abril 2019. URL: http://journals.openedition.org/ ccec/6666. doi: 10.4000/ccec.6666.

Núñez Seixas, Xosé Manuel, Camarada invierno. Experiencia y memoria de la División Azul (1941-1945), Barcelona, Crítica, 2016.

Ollaquindía, Ricardo, «La Oficina de Prensa y Propaganda Carlista de Pamplona al comienzo de la guerra de 1936», Príncipe de Viana, 205 (Pamplona, 1995): 485-505.

Ortega López, Teresa María, «Conservadurismo, catolicismo y antifeminismo: la mujer en los discursos del autoritarismo y el fascismo (1914-1936)», Ayer, 71/3 (Madrid, 2008): 53-83. 
Oviedo Silva, Daniel, “"Juro por Dios y declaro por mi honor”: Verdad, impostura y estrategias auto exculpatorias en las declaraciones de la posguerra madrileña», en Madrid, una ciudad en guerra (1936-1948), Madrid, La Catarata, 2016: 159-213.

Palacio Atard, Vicente, «La quinta columna, la movilización popular y la retaguardia», en Aproximación histórica a la guerra española, Madrid, Universidad Complutense de Madrid, 1970: 241-275.

Pastor Petit, Domenec, La cinquena columna a Catalunya, 1936-1939, Barcelona, Galbas, 1978.

Pastor Petit, Domenec, Traidors a Catalunya, la cinquena column, Barcelona, Editorial Base, 2006.

Pastor Petit, Domenec, Resistencia y sabotaje en la Guerra Civil. Espías, agentes y quintacolumnistas, Barcelona, Robinbook, 2013.

Powelson, John P., The Moral Economy, Ann Arbor, University of Michigan Press, 1998.

Preston, Paul, «Franco: Anatomía de un dictador», en El Franquismo: El Régimen y la Oposición, Toledo, Ministerio de Educación y Cultura/Comunidad de Castilla La Mancha, 2000: 21-32.

Preston, Paul, Palomas de guerra. Cinco mujeres marcadas por el enfrentamiento bélico, Barcelona, Plaza \& Janés, 2001.

Quezada Quiroz, Claudia, «La mujer cristera en Michoacán, 1926-1929», Historia y Memoria, 4 (Alicante, 2012): 191-223.

Ramos Palomo, M. ${ }^{a}$ Dolores, «¿Madres de la Revolución? Mujeres en los movimientos sociales españoles, 1900-1930», en Georges Duby y Michelle Perrot (eds.). Historia de las mujeres. Siglo XX, Madrid, Santillana, 2000: 709-722.

Rebollo Mesas, Pilar, El servicio social de la mujer en la provincia de Huesca (19371978), Zaragoza, Instituto de Estudios Altoaragoneses, 2003.

Rodríguez López, Sofía, «Secularization versus the weight of Catholic Tradition among Spanish Women in the $20^{\text {th }}$ Century», en Barry Kosmin (ed.). Secularism, Women \& the State: The Mediterranean World in the 21st Century, Connecticut, Institute for the Study of Secularism in Society and Culture/Trinity College, 2009: 177-194.

Rodríguez López, Sofía, El patio de la cárcel. La Sección Femenina de FET-JONS en Almería (1937-1977), Sevilla, Centro de Estudios Andaluces, 2010.

Rodríguez López, Sofía y Cazorla Sánchez, Antonio, «Blue Angels: Female Fascist Resistants, Spies and Intelligence Officers in the Spanish Civil War, 1936-1939», Journal of Contemporary History, 53/4 (Londres, 2018): 692-713.

Rodríguez Velasco, Hernán, Una derrota prevista. El espionaje militar republicano en la Guerra Civil española (1936-1939), Granada, Comares, 2012.

Ruiz Franco, Rosario, ¿Eternas menores? Las mujeres en el franquismo, Madrid, Biblioteca Nueva, 2007.

Ruiz-Berdún, Dolores, «Matronas y enfermeras a pie de guerra: la invisibilidad del trabajo sanitario femenino durante la Guerra Civil (1936-1939)», en Francisco González (coord.). Ciencia y Técnica entre la paz y la guerra, 1714, 1814, 1914, Madrid, Sociedad Española de Historia de las Ciencias y de las Técnicas, 2015, vol. I: 523-530.

Ruiz-Berdún, Dolores et al., «Entre la propaganda y el espionaje: la Delegación Especial para la Información de Residentes en Territorio Liberado (DIDREM) en la

Hispania, 2020, vol. LXXX, n. ${ }^{\circ}$ 265, mayo-agosto, págs. 531-561, ISSN: 0018-2141, e-ISSN: 1988-8368

https://doi.org/10.3989/hispania.2020.015 
España de la Guerra Civil (1936-1939)», Saitabi. Revista de la Facultat de Geografia i Historia, 66 (Valencia, 2016): 205-228.

Sánchez Blanco, Laura, Rosas y margaritas. Mujeres falangistas, tradicionalistas y de Acción Católica asesinadas en la Guerra Civil, Madrid, Actas, 2016.

Schell, Patience A., "An Honorable Avocation for Ladies: The Work of the Mexico City Unión de Damas Católicas Mexicanas, 1912-1926», Journal of Women's History, 10/4 (Baltimore, 1999): 78-103.

Schell, Patience A., "Gender, Resistance and Mexico's Church State Conflict», en New Approaches to Resistance in Brazil and Mexico, Durham/Londres, Duke University Press, 2012: 184-203.

Scott, James, The Moral Economy of the Peasant: Rebellion and Subsistence in Southeast Asia, New Haven, Yale University, 1977.

Scott, James, Weapons of the Weak: Everyday Forms of Peasant Resistance, New Haven, Yale University Press, 1987.

Serrat Bonastre, Francisco, Salamanca, 1936. Memorias del primer ministro de Asuntos Exteriores de Franco, Barcelona, Crítica, 2014.

Souto Kustrín, Sandra, «Y ¿Madrid? ¿Qué hace Madrid?». Movimiento revolucionario y acción colectiva (1933-1936), Madrid, Siglo XXI, 2004.

Suárez Cortina, Manuel (ed.), México y España. Historia y memoria de dos siglos (1810-2010), Madrid, Síntesis, 2014.

Suárez Cortina, Manuel et al. (eds.), Cuestión religiosa. España y México en la época liberal, Santander, Universidad de Cantabria, 2013.

Suárez Fernández, Luis, Crónica de la Sección Femenina y su tiempo, Madrid, Nueva Andadura, 1993.

Thompson, Edward P., Costumbres en común. Estudios en la cultura popular tradicional, Barcelona, Crítica, 2001 [1991, original inglés].

Uribarri, Manuel, La Quinta Columna Española. Verdad y Justicia, La Habana, Biblioteca Pro-Democracia Española, 1943.

Von Saldern, Adelheid, «Victims or perpretators? Controversies about the role of Women in the Nazi State», en David E. Crew (ed.). Nazism and German Society 1933-1945, Londres, Routledge, 1994: 141-165.

Wingeate Pike, David, Franco y el Eje Roma-Berlín-Tokio. Una alianza no firmada, Madrid, Alianza, 2010.

Yusta Rodrigo, Mercedes, «Género y antifascismo en España: de la II República a la Guerra Fría (1931-1950)», Anuario IESH, 28 (Tandil, 2013): 227-247.

Recibido: 07/04/2019

Aceptado: 18/03/2020 